\title{
Accelerating uptake of voluntary, rights-based family planning in developing countries
}

Kazuyo Machiyama

Francis Obare

Population Council

Venkatraman Chandra-Mouli

Doris Chou

Mario Festin

See next page for additional authors

Follow this and additional works at: https://knowledgecommons.popcouncil.org/departments_sbsr-rh

Part of the Demography, Population, and Ecology Commons, Family, Life Course, and Society Commons, International Public Health Commons, Maternal and Child Health Commons, and the Women's Health Commons How does access to this work benefit you? Let us know!

\section{Recommended Citation}

Machiyama, Kazuyo, Francis Obare, Venkatraman Chandra-Mouli, Doris Chou, Mario Festin, Rajat Khosla, James Kiarie, Lale Say, and Nandita Thatte. 2018. "Accelerating uptake of voluntary, rights-based family planning in developing countries," Family Planning Evidence Brief. Geneva: World Health Organization. 


\section{Authors}

Kazuyo Machiyama, Francis Obare, Venkatraman Chandra-Mouli, Doris Chou, Mario Festin, Rajat Khosla, James Kiarie, Lale Say, and Nandita Thatte 


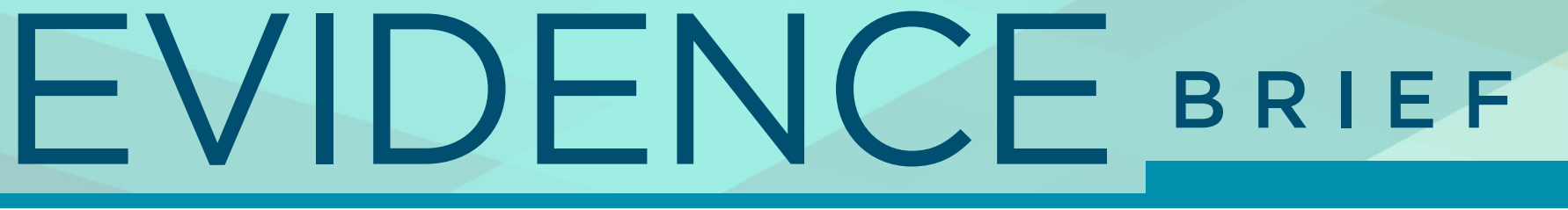

\section{Accelerating uptake of voluntary, rights-based family planning in developing countries}

$\rightarrow$ A woman's ability to choose whether and when to become pregnant directly affects her health and well-being. Voluntary family planning saves lives and accelerates sustainable human and economic development (1). It leads to the realization of human rights and promotes the empowerment of women and adolescent girls, enabling them to complete their education, seize better economic opportunities, and fulfil their capabilities. Enabling women and adolescent girls to make decisions about their health and future is one of the most cost-effective ways of creating more sustainable and thriving societies around the world.

To meet the FP2O2O and Sustainable Development Goals, significant investments are required by countries and donors in the following priority areas: sustainable financing, reaching all adolescents, expanding availability of services to the poorest and hard-to-reach populations, improving the quality of services, increasing the range of methods available, strengthening procurement procedures and supply chains, broadening social and behaviour change communication interventions, and sustaining research and development investments in contraceptive methods and their delivery.

The Sustainable Development Goals (SDGs) make specific references to family planning in regard to health and well-being, gender equality, and women's empowerment. Ensuring that all women and adolescent girls have access to high-quality, rights-based family planning services contributes towards achieving these goals and realizing targets related to other SDGs. Accelerated fertility decline through effective family planning programmes slows rapid population growth, contributing to the SDGs related to the economy, environment, and development (2).

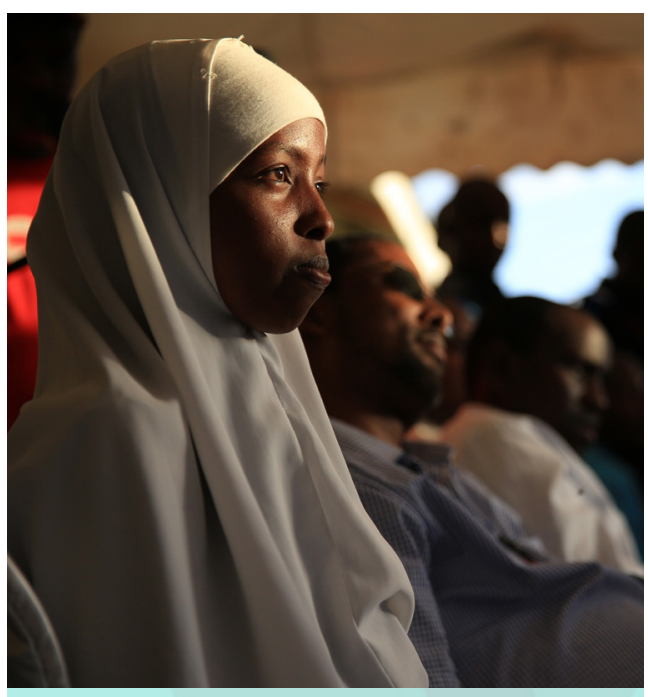

To meet the FP2020 and Sustainable Development Goals, significant investments are required by countries and donors in the following priority areas:

$\rightarrow$ Sustainable financing

$\rightarrow$ Reaching all adolescents

$\rightarrow$ Expanding availability of services to the poorest and hard-to-reach populations

$\rightarrow$ Improving the quality of services

$\rightarrow$ Increasing the range of methods available

$\rightarrow$ Strengthening procurement procedures and supply chains

$\rightarrow$ Broadening social and behaviour change communication interventions

$\rightarrow$ Sustaining R\&D investments in contraceptive methods and their delivery 
This brief summarises evidence on the benefits of family

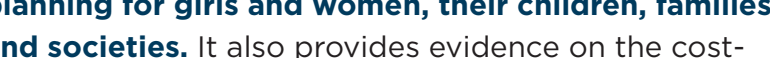
effectiveness of family planning programmes; discusses reasons for unmet need for contraception and identifies ways to reduce unmet need and discontinuation; and describes progress in meeting FP202O and the Sustainable Development Goals.

HUMAN RIGHTS-BASED APPROACH TO FAMILY PLANNING

International and regional human rights treaties and national constitutions and laws provide legally binding obligations for states to ensure timely and affordable access to quality family planning information, services, and contraceptive commodities for all. The human right to the highest attainable standard of health, which includes access to health services and health-related information, cannot be fulfilled without promotion and protection of the rights to education and information.

Human rights standards for family planning information and service delivery include nondiscrimination; availability accessibility, acceptability, and quality of family planning information and services; in and confidentiality; participation; and accountability.

$\rightarrow$ Access to quality family planning services is both a right and a smart investment for governments, communities, and families. Fulfilling and protecting this right is critical for achieving the SDGs, including gender equality, as well as more inclusive economic development.

\section{BENEFITS OF FAMILY PLANNING}

\section{Health benefits}

Family planning has clear health benefits, principally the prevention of unintended pregnancies and reductions in maternal and infant mortality and morbidity. An estimated 214 million women in the developing world want to delay or prevent pregnancy but are not using a modern method of contraception (3). Providing access to these women would prevent 67 million unintended pregnancies and reduce induced abortions from 48 million to 13 million. It would reduce maternal deaths by 76,000 per year, newbo deaths from 2.9 million to 660,000 per year and HIV infections in newborns from 130,000 to 9,000 (3).

Family planning allows spacing of pregnancies and can delay pregnancies in young women. Current use of modern contraceptives prevents an estimated 307 millio unintended pregnancies annually among adolescent girls and women in developing regions. Access to family plannis is especialy critcal for acloscents with unmet among aldescents aged 15-19 would reduce unintended

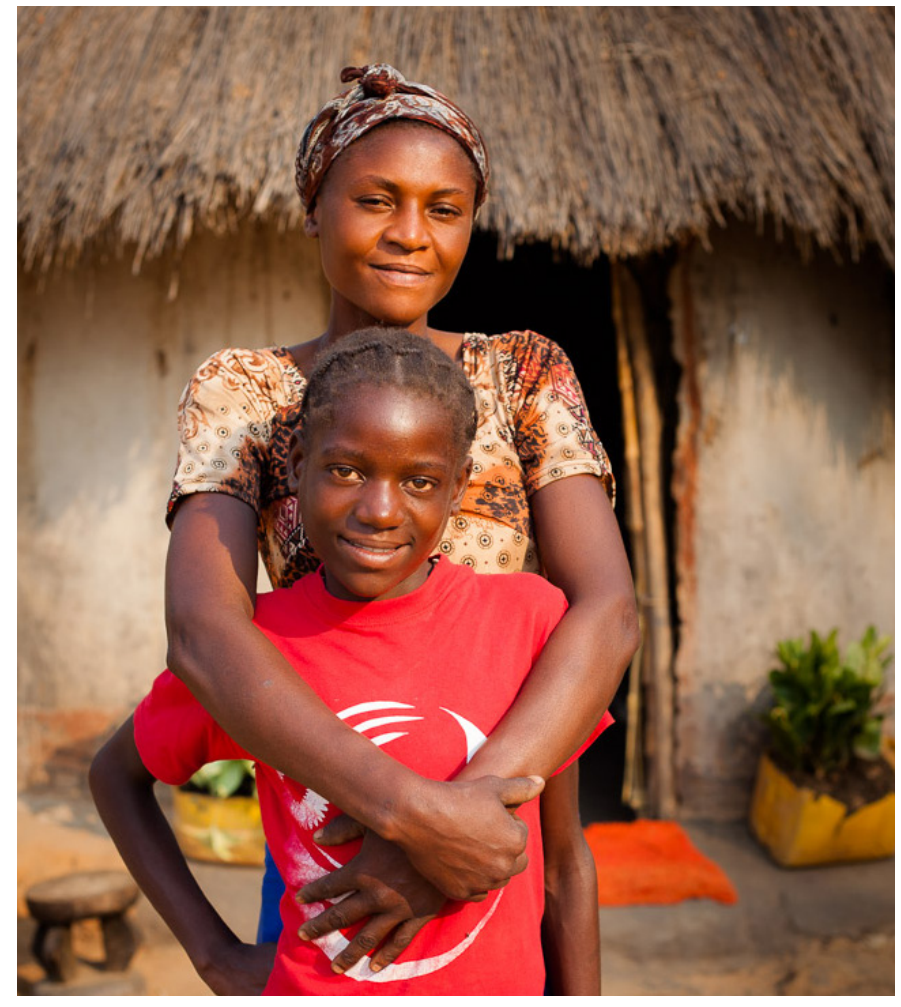

countries deny adolescents access to family planning they may be forced to seek unsafe and clandestine procedures or, finavallable, may resort to suicide rather than reveal their pregnancy status (10).

Social, economic, and environmental benefits One of the key social benefits of family planning is for all children and in gender (to invest more in each child and enables children to stay in schoo longer than children with many siblings (7). Early and for dropping out of school in some countries (11), and preventing early pregnancies will help girls remain in of fertility decline and facilitates human and economic development (12).

Young people (aged 15-24 years) constitute about onethird of the working-age population across Africa, but $50 \%$ of them are either unemployed or economically inactive (13). Investments in youth through education, skill development, and employment opportunities are essentia for seizing the window of opportunity provided by the demographic dividend (14). Rapid fertility decline throug strong rights-based family planning programmes is a crucial prerequisite for attaining the dividend. In 2017 the African Union launched the policy "Harnessing the Demographic Dividend Through Investments in Youth". This political commitment in African Union countries has led to greater investments in family planning programmes.

The relationship between population growth, human and economic development, and the environment is multifaceted. The United Nations estimates that by 2050 th world's population wil increase by 2.4 bilion people, Whith over $90 \%$ of the growth in developing countries (15). Rapid population growth exerts considerable pressure on individuals, communities, and the planet. Environmental changes, such as global warming, Changes in water availamay, sor dectly affect levels of a griculural produse chang These changes would have a lar impact on sub- (16). Africa, where two-thirds of ange impact on sub-Saharan Africa, where Widespread weather anomalies increase the agriculure. Widespread weather anomalies increase the international migration in sub-Saharan Africa and elsewhere (17)

$\rightarrow$ Prevention of unintended pregnancy in both the developed and developing world is one

of the most cost-effective ways of mitigating negative environmental impacts (18).

\section{A cost-saving investment}

The estimated annual cost of modern contraceptive services in developing regions, covering 671 million women who use modern methods, is $\$ 6.3$ billion, including direct an indirect costs. This is less than one dollar (\$1.01) per person in developing regions (3). Meeting the needs of all women

a lonited autonomy. They are more likely to have a

can place them and their children at risk for poor health

outcomes (9). Additionally, legal systems in some

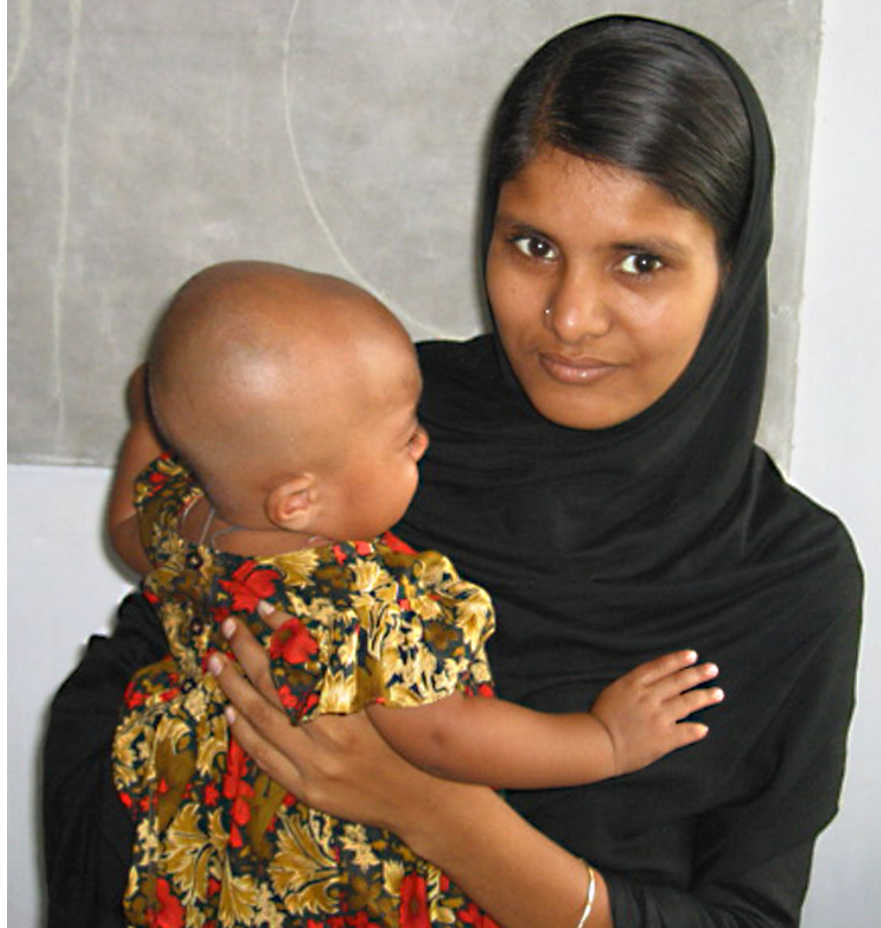
current users and women with unmet need-would cost around $\$ 12$ billion annually, or $\$ 1.93$ per person (3). Preventing unintended pregnancies through use of moder contraception is much cheaper than the cost of care for unintended births. Spending one additional dollar for contraceptive services above the current level reduces the

\section{UNMET NEED FOR FAMILY} PLANNING, NON-USE, AND DISCONTINUATION

The figure of 214 million women in developing countries with an unmet need for family planning (3) includes wome who have never used contraception and those who have discontinued use of a method. As overall contraceptive use increases, addressing reasons for discontinuation and failure to switch to an alternative method becomes more important. Levels of contraceptive discontinuation vary by duration of use and method. More than one in three (38\%) women in 19 developing countries discontinue a method within 12 months, $55 \%$ within 24 months, and $64 \%$ within 36 months (19).

$\rightarrow$ Contraceptive discontinuation is higher for short-acting methods (e.g., injectables, pills and condoms) than for long-acting reversible contraceptives (LARCs) (e.g., implants,

IUDs), with discontinuation rates of $50 \%$ for condoms, $44 \%$ for pills, $41 \%$ for injectables, and $13 \%$ for IUDs within 12 months of use (19).

Women who are young, less educated, from poorer households, or from rural areas are more likely to have unmet need for contraception and a higher likelihood of 
discontinuation (20,21). Sexually active unmarried women he high levels of unmet need, contributing to more than Africa (22). This proportion will tend to rise as age at marriage and/or levels of premarital sex increase.

The high levels of unmet need and contraceptive discontinuation indicate that women and girls need greater support to newly adopt or switch to appropriate an their fertility preferences, sexual behaviour, and health.

Reasons for non-use or discontinuation Lack of knowledge, sociocultural obstacles, and barriers to obtaining services are major reasons for non-use in populations with low contraceptive prevalence.

$\rightarrow$ As modern contraceptive prevalence (mCPR) increases, reasons for non-use shift to health concerns and side effects of specific, primarily hormonal, methods and a lack of perceived risk of unintended pregnancy (22). The dominant reason for discontinuation is method-related, particularly fear of side effects and health concerns.

Health and method-related reasons. Side effects and non-use and discontinuation Menstrua irrens for weight gain, nausea, and fear of other health risks are major causes of concern. Concerns about side effects in settings with high contraceptive prevalence are mostly derived from experience rather than perception (20). Fear that contraception causes infertility is also commonly reported. Infertility is often highly stigmatized, resulting in worry about potential harm to future childbearing (20).

Lack of knowledge about contraception overall is less significant barrier to use, however, inadequate information about specific methods remains a barrier. Lack of awareness of certain methods and supply sources appears more important than previously claimed (23). Improving knowledge among populations with low $\mathrm{mCPR}$ is essential-for example, in remote rural areas and in West and Middle Africa (20).

Low perceived risk of pregnancy as a result of infrequent sex is often cited as a reason for non-use, particularly in areas where labour migration is common $(20,24)$. A menorh wea or breastfeeding is sometim period.

Socio-cultural barriers. Opposition to contraception can include women's own opposition to contraception or to specific methods or broader cultural opposition family and adherence to social norms prevent some women from ache to social and being advised not to use or knowing dissatisfied

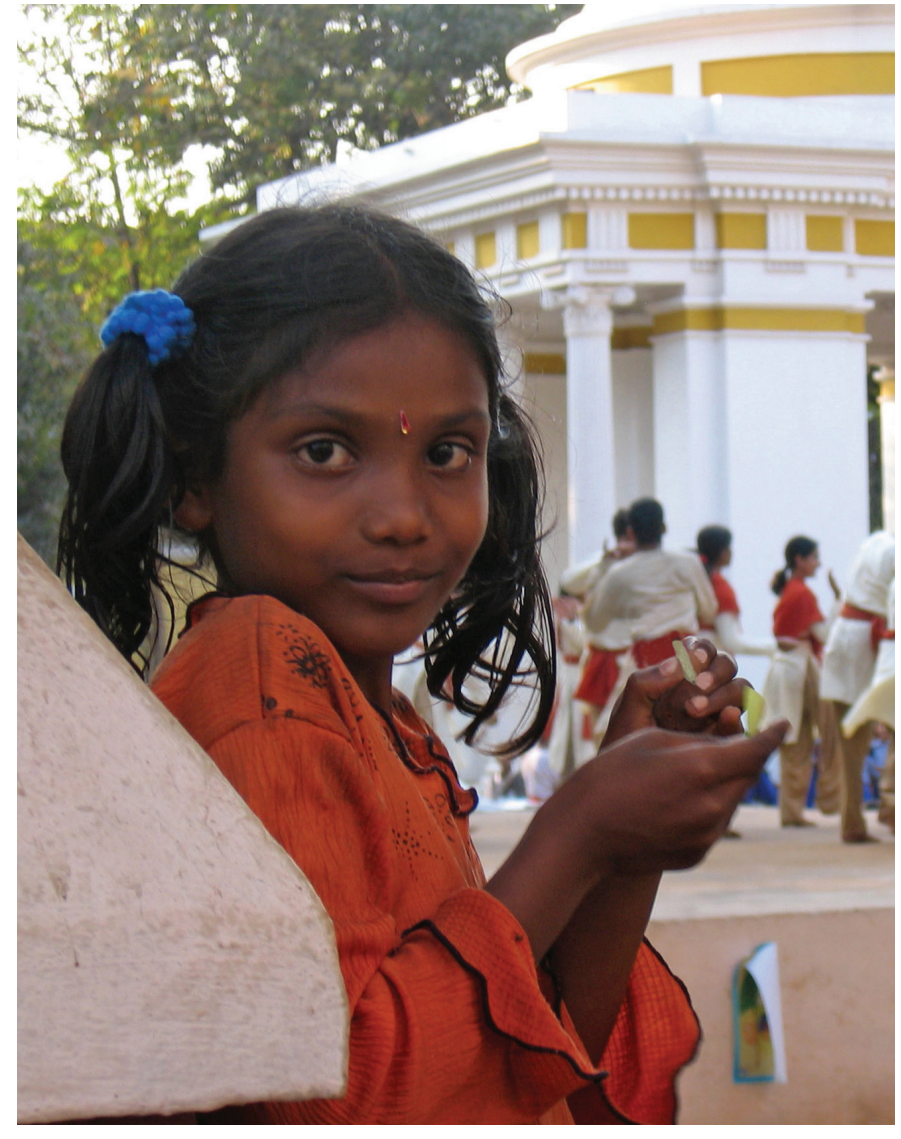

users through social networks may also discourage uptake and continuation of contraception (25).

Low levels of motivation to avoid pregnancy and ambivalence or uncertainty about pregnancy intentions, which may partly derive from cultural or religious beliefs or from norms about ideal family size, also prevent women from using a contraceptive method.

Barriers to obtaining services. Stockouts of contraceptive commodities are another reason for non-use and/or discontinuation. When a preferred method is not available, women are more likely to discontinue use (26).

Provider biases about contraceptive use in general-and about provision of specific methodsare common, especially within services for young people. Some healthcare workers are hesitant to provide contraceptive methods to unmarried women and adolescents, and are particularly reluctant to provide long-acting reversible contraceptives (LARCs) to nulliparous women, despite clear evidence that their use is safe and Hective, regardless of party $(27,28,29.30)$. Because of blases among some providers, women and adescents may be unable to receive methods themselves.

Distance to services and cost of obtaining

they are provided free,

are frequently barriers for women, and especially adolescents, living in remote rural areas (31). In their cost can be a barrier, particularly for LARCs and sterilisation and for all methods among young people.

\section{HOW CAN COUNTRIES}

REDUCE UNMET NEED AND

DISCONTINUATION?

No single intervention by itself will be effective in reducing unmet need for family planning and method discontinuation. Most successful programmes have created political and social support for family planning throughout the population and ensured that a wide range of methods is accessible and affordable through a variety of delivery systems.

$\rightarrow$ Explicitly addressing social norms concerning family planning, method-related concerns

about specific methods, and barriers to access can reduce unmet need for contraception.

\section{Addressing lack of knowledge, myths, and}

misconceptions

Information, education, and communication (IEC) efforts, including a combination of mass media and in

Promoting communication between couples and among friends and with health professionals about method characteristics, especially side effects, can support continued use through method switching if problems are experienced. Engaging male community and religious leaders can also enhance support for use of contraceptio broadly within communities $(34,35)$

mproved counselling, including how to manage side (litching if problems occur and improve client satisfaction with contraceptive use (36). Providers must anticipate some level of discontinuation among all of their clients and inform women and adolescents about the option of switching to alternatives when first counselling about starting a new method.

\section{Improving access to services}

Social marketing makes contraceptive commodities more accessible and affordable through private-sector outlets such as pharmacies and shops. Incorporation of social marketing to complement public sector clinic outlets increases clients' knowledge of and access to contraceptive methods, particularly pills and condoms (37). The reduced international funding for social marketing needs to be replaced by domestic resources.

Mobile outreach services have increased contraceptive use particularly in areas where access through health facilities and community-based programmes is limited or healt

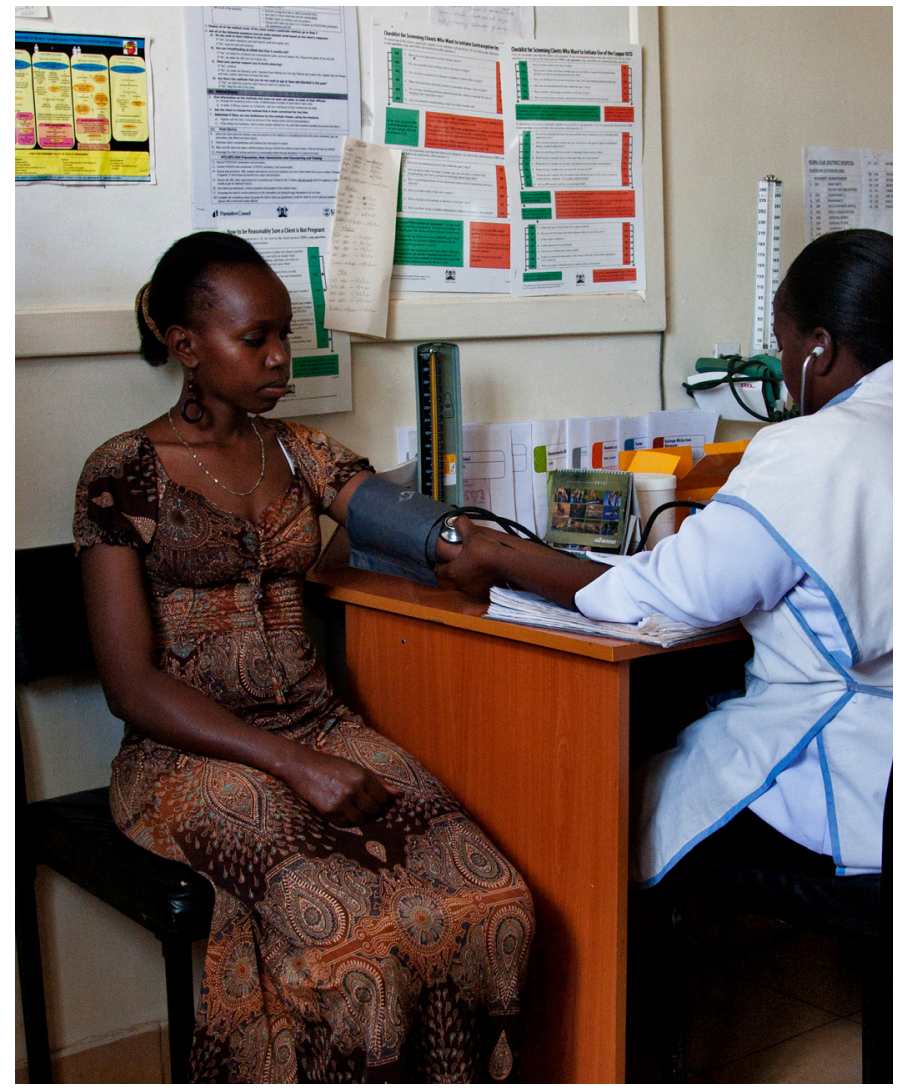

worker shortages limit the provision of certain methods, and when the services are higher quality than those Mobile outreach services can also expand method choices by providing long-acting and permanent methods in hardto-reach areas (38).

$\rightarrow$ Task-sharing between different cadres or shifting certain service delivery tasks to

lower-level healthcare workers improves the availability of some methods (39).

Community health worker (CHW) programmes increase contraceplive use in places where access to clinic-based services is limited (40), and engaging drug shops and pharmacies in the provision of contraception has led to increased use, particularly among young people and in urban areas (41).

Integrating family planning with other reproductive, maternal, and newborn health services such as

immunization, antenatal and immediate post-delivery care, and HIV services contributes to increased use of methods. The impact depends, however, on the overall service structure, quality of counselling, volume of clients, and

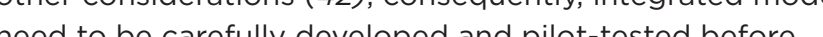
being implemented at scale.

Contraceptive commodity procurement and supply systems need to be strengthened and better integrated with broader health commodity systems to reduce stockouts and ensure that a wide range of methods is consistently 


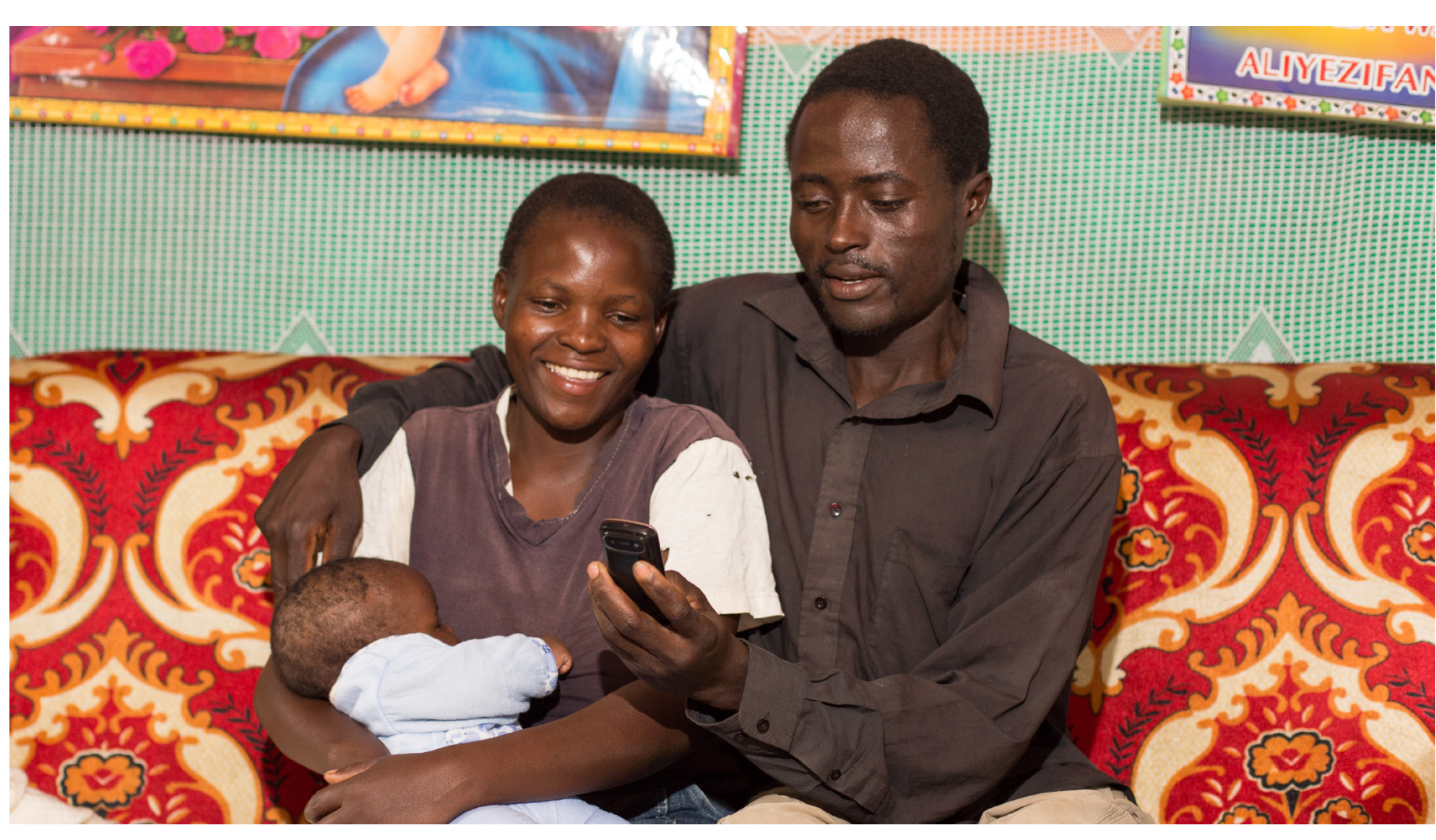

low fertility with a method mix skewed towards a small number of methods, ensuring availability of a range of contraceptives allows women to use their preferred method and to switch if a chosen method proves to be unacceptable (43).

LARCs have lower discontinuation rates and for many women can be more effective than short-acting methods. women can be more effective than short-acting met
Increasing the availability of LARCs, especially to Increasing the availability of LARCs, especially to
postpartum women at public-sector maternal and child postpartum women at public-sector maternal and child health facilites or through mobile outreach services to geographically dispersed populations, can lead to greater use among previously underserved populations and high cost of obtaining these methods from quality-accredited

facilities can also increase use by reducing multiple barriers (44).

PROGRESS IN FAMILY PLANNING USE SINCE 2012

In July 2012, more than 20 countries made commitments and $\$ 2.6$ billion was pledged in increased resources to enable 120 million more women and girls to use contraceptives by 2020. Three years later the 2030 Sustainable Development Goals were launched and include targets to ensure universal access to sexual and reproductive healthcare services and rights, including family planning (45). As countries move towards achieving these ambitious goals, it is important to assess the evidence of what has worked, what has not worked, and to identify areas for further investment. The number of women who want to avoid a pregnancy but are not using

an effective contraceptive method decreased from 225
million in 2014 to 214 million in 2017 (46).

Between 2012 and 2015 the number of modern contraception users increased significantly more quickly than would have been expected from historical trends (46). Galvanised efforts have improved policies and strengthened services at the country level. More than 90 partners, including 38 countries, have made commitments to expand access to voluntary, rights-based, high-quality family planning. At the country level, effective partnerships have address challenges (46). Improved data tools and resources have led to better country-level and subnational reporting, allowing countries to identify current trends and guide their actions in the coming years (47). There has been a steady increase in donor government and domestic funding for family planning since 2012 (48).
CHALLENGES TO ACHIEVING FP2020 GOALS

Despite the progress made, the demand for family planning that is satisfied with modern contraception remains below $50 \%$ in many low-income FP2O20 countries $(3,46)$.

Moreover, a limited range of contraceptive methods has prevented women from obtaining their preferred methods, including LARCs that suit their particular needs. In $37 \%$ o focus countries, one method accounts for 50\% or more of contraceptive use among women (46). Stockouts remain a problem, particularly in hard-to-reach areas. In none of the countries wh hata were at least three methods avallable in al the prinary level faclities surveyed. and their reluctance to provide LARCs to nulliparous womer are common.

Limited counselling about health concerns and side effects and lack of attention to ensuring high quality of services can discourage potential new users and result in rapid discontinuation without switching. Many countries need to improve the quality of counselling to enable more women and girls to exercise informed choice and to change methods when needed. Several countries with low prevalence of modern contraception have large numbers of women and adolescents living in humanitarian settings where the provision of FP services is inadequate.

\section{CONSIDERATIONS FOR}

ACCELERATING UPTAKE OF

VOLUNTARY, RIGHTS-BASED

FAMILY PLANNING IN

\section{DEVELOPING COUNTRIES}

To improve the proportion of demand for FP that is satisfied through effective contraceptive methods and thereby meet the FP2O2O and Sustainable Development Goals, the evidence presented here suggests that significant investments are required by countries and donors in the following priority areas:

Ensuring sustainable financing, primarily from domestic engaged civil society to support country objectives and sources, for services and commodities

Reaching all adolescents with accurate information and services

\section{REFERENCES}

Cleland C, Bernstein S, Ezeh A, Faundes A, Glasier A, Lets J Famly plan (O549):1810-27.

Starbird E, Norton M and Marcus R. Investing in family Goals. Glob Health Sci Pract. 2016; 4(2): 191-210.

3. Adding it up: investing in contraception and maternal and newborn health. 2017. Guttmacher Institute: New York, USA

4. Darroch JE, Woog V, Bankole A, Ashford LS. Adding it up: costs and benefits of meeting the contraceptive needs of adolescents. 2016. Guttmacher Institute: New York, USA.

5. Conde-Agudelo A, Rosas-Bermúdez A, Kafury-Goeta AC. 2006. Birth spacing and the risk of adverse perinata outcomes: a meta-analysis. Journal of the American Medical Association 295, 1809-1923

6. WHO. Report of a WHO technical consultation on birth spacing. Geneva, Switzerland, 13-15 June 2005.

Rutstein SO, Johnson K, Conde-Agudelo A \& RosasBermudez A. 2005. Effect of birth spacing on infant and child mortality: a systematic review and meta-analysis. In World Health Organization Consultation and Scientific Review of Birth Spacing. WHO, Geneva, 13-15th June 2005 8. WHO. 2013, WHO: Geneva.

9. Lopez et al. 2010; WHO 2016 FP factsheet

10. WHO, Global Health Estimates 2015

11. Birungi H, Undie C, Mackenzie I, Katahoire A, Obare F. Machawira F. Education sector response to early and unintended pregnancy: a review of country experiences in sub-Saharan Africa. 2015

12. Jejeebhoy SJ. 1995. Women's Education, Autonomy, and Reproductive Behaviour: Experience from Four Developing Oxford: Clarendon Press.

13. AfDB, OECD, UNDP. African Economic Outlook 2017: Entrepreneur and industrialization. 2017. AfDB, OECD, UNDP.

Assembly of the Union Twenty- Sixth Ordinary Session 3031 January 2016, Addis Ababa, Ethiopia. AU roadmap on Harnessing the Demographic Dividend through investing in Youth. 2017.

15. United Nations, Department of Economic and Social Affairs, Population Division. 2015. World Population Prospects: The 2015 Revision, Key Findings and Advance Tables. Working Paper No. ESA/P/WP.241.

16. Godfray H, Charles J, et al. 2010. "Food security: The challenge of feeding 9 billion people," 327: 812-818.

Marchiori L, Maystadt JF, Schumacher I. 2012. The impact of weather anomalies on migration in sub-Saharan Africa. Journal of Environmental Economics and Management 63, 355-374. especially the urban poor, and other hard-to-reach populations including those in humanitarian settings and rural areas

Improving the quality of services to reduce discontinuation and increase switching

Increasing the range of methods available, either at the point of delivery or through referral

Strengthening procurement procedures and supp

Broadening interventions in social and behaviour change communication to reach larger audiences, especially through digital technologies

Sustaining R\&D investments in innovations in contraceptive methods and their delivery.
18. Wheeler $\mathrm{D}$, Hammer $\mathrm{D}$. The economics of population policy 2010. Center for Globad Development Working Paper 2010. Center for Global Development Working Paper

Ali MM JG Cletond and IH Shah, 2012. WHO: Geneva, Switzerland.

20. Sedgh, G., LS Ashford, and R Hussain, 2016. Guttmacher

政,

22. Cleland, J, S Harbison, and IH Shah, Studies in family planning, 2014. 45(2): p. 105-122. 
23. Machiyama K, Cleland J. Studies in Family Planning, 2014. 45(2): p. 203-226.

24. Casterline JB, AE Perez, and AE Biddlecom, Studies in Family Planning,, 1997. 28(3): p. 173-91.

25. Aryeetey R, AM Kotoh, and MJ Hindin, Afr J Reprod Health, 2010. 14(4 Spec no.): p. 26-31.

26. Burke HM, C Ambasa-Shisanya, Afr J Reprod Health, 2011. 15(2): p. 67-78.

27. Hebert, LE, et al., J Fam Plann Reprod Health Care, 2013. 39(1): p. 29-35.

28. Nalwadda, G., et al., BMC Health Serv Res, 2011. 11: p. 220.

29. Robinson, N., et al., Health Care Women Int, 2016. 37(2): p. 197-215.

30. Sidze, E.M., et al., Int Perspect Sex Reprod Health, 2014. 40(4): p. 176-83.

31. Tsui, AO and LH Ochoa, , in , J.F. Phillips and J.A. Ross, Editors. 1992, Oxford University Press: London. p. 222-256.

32. Cleland, J, et al., Lancet, 2006. 368(9549): p. 1810-27.

33. Hindin, MJ, et al., J Adolesc Health, 2016. 59(3 Suppl): p. S8-S15.

34. Institute for Reproductive Health Georgetown University, 2014, Institute for Reproductive Health Georgetown University: Washington, DC.

35. Shattuck, D, et al., Am J Public Health, 2011. 101(6): p. 108995.

36. Samandari G and KA O'Connell, Women Health, 2011. 51(3): p. 256-78.

37. High Impact Practices in Family Planning (HIP). 2013; Available from: http://www.fphighimpactpractices. org/resources/social-marketing-leveraging-privatesectorimprove-contraceptive-access-choice-and-use.

38. High Impact Practices in Family Planning (HIPs). 2014; Available from: http://www.fphighimpactpractices.org/ resources/mobile-outreach-services.

39. Polus, S, et al., Reprod Health, 2015. 12: p. 27.

40. High-Impact Practices in Family Planning (HIPs). 2015; Available from: http://www.fphighimpactpractices.org/ resources/community-health-workers-bringing-familyplanning-services-where-people-live-and-work.

41. High-Impact Practices in Family Planning (HIP). 2013; Available from: http://www.fphighimpactpractices. org/resources/social-marketing-leveraging-privatesectorimprove-contraceptive-access-choice-and-use.

42. High-Impact Practices in Family Planning (HIP). 2013; Available from: http://www.fphighimpactpractices.org/ resources/family-planning-and-immunizationintegrationreaching-postpartum-women-family-planning.

43. Ross JA and J Stover, Global Health: Science and Practice, 2013. 1(2): p. 203-212.

44. Bajracharya A, et al., Glob Health Sci Pract, 2016. 4 Suppl 2: p. S109-21.

45. Sustainable development goals 2030 (http://www.un.org/ sustainabledevelopment/health/).

46. FP2O2O 2015-2016 progress report Momentum at the Midpoint (http://progress.familyplanning2020.org/).

47. Donor Government Assistance for Family Planning in 2015The Henry J Kaiser Family Foundation (http://files.kff. org/attachment/Report-Donor-Government-Assistancefor-Family-Planning-in-2015).

48. Stover J and Sonneveldt E. Progress toward the Goals of FP2O2O, Studies in Family Planning 48(1).Bajracharya, A. et al. 2016. TITLE? Global Health: Science and Practice 4(Suppl 2): S109-121.
49. Sustainable Development Goals 2030 (http://www.un.org/ sustainabledevelopment/health/).

50. FP2020. YEAR? 2015-2016 Progress Report: Momentum at the Midpoint. http://progress.familyplanning2020.org/.

51. Kaiser Family Foundatoin 2015. Donor Government Assistance for Family Planning in 2015. Menlo Park, CA: The Henry J Kaiser Family Foundation. http://files.kff. org/ attachment/Report-Donor-Government-AssistanceforFamily-Planning-in-2015.

52. Stover, J. and E. Sonneveldt. YEAR? "Progress toward the goals of FP2020," Studies in Family Planning 48(1): pp?.

Authors: Kazuyo Machiyama (London School of Hygiene and Tropical Medicine); Francis Obare (Population Council); Venkatraman Chandra-Mouli, Doris Chou, Mario Festin, Rajat Khosla, James Kiarie, Lale Say, Nandita Thatte (World Health Organization).

This is one of seven Family Planning Evidence Briefs prepared for the Family Planning Summit held in London on July 11, 2017. The briefs highlight evidence and provide research and programme considerations for improving access to family planning and reducing unintended pregnancy. Programme considerations are based on the expert views of the authors, who undertook desk reviews drawing on existing evidence.

\section{Family Planning Evidence Briefs}

- Accelerating uptake of voluntary, rights-based family planning in developing countries (overview) (Updated October 2018)

- Family Planning Financing (Updated October 2018)

- Reducing early and unintended pregnancies among adolescents (Updated October 2018)

- Improving family planning service delivery in humanitarian crises

- Ensuring contraceptive security through effective supply chains

- Expanding contraceptive choice and method mix (Updated October 2018)

- Partnering with the private sector to strengthen provision of contraception

The authors alone are responsible for the views expressed in this article and they do not necessarily represent the views, decisions or policies of the institutions with which they are affiliated.

Family Planning Evidence Brief - Accelerating uptake of voluntary, rightsbased family planning in developing countries: WHO/RHR/18.28

(c) World Health Organization 2018. Some rights reserved. This work is available under the CC BY-NC-SA 3.0 IGO license.

For more information, please contact: Department of Reproductive Health and Research, World Health Organization, Avenue Appia 20 ,

$\mathrm{CH}-1211$ Geneva 27, Switzerland

E-mail: reproductivehealth@who.int

Website: www.who.int/reproductivehealth

Twitter: @HRPresearch

This material has been funded by UK aid from the UK government; however, the views expressed do not necessarily reflect the UK government's policies.

Prepared July 2017. Updated October 2018 